\title{
Immunosuppressive Drug Levels in Liver Transplant Recipients: Impact in Decision Making
}

\author{
Themistoklis Kourkoumpetis, MD, MPH ${ }^{1}$ Josh Levitsky, MD² \\ ${ }^{1}$ Division of Gastroenterology and Hepatology, Baylor College of \\ Medicine, Houston, Texas \\ 2 Division of Gastroenterology and Hepatology, Northwestern \\ Memorial Hospital, Chicago, Illinois \\ Address for correspondence Josh Levitsky, MD, NMH/Arkes Family \\ Pavilion 19th floor, 676 N Saint Clair, Chicago, IL 60611 \\ (e-mail: Josh.Levitsky@nm.org).
}

Semin Liver Dis 2019;39:414-421.

\begin{abstract}
Keywords

- immunosuppression

- liver transplant

- drug level monitoring

- immune monitoring

To prevent rejection, liver transplant providers largely base their management decisions on their clinical impression and pharmacokinetics. Clinical impression relies on assessing graft function, liver enzymes, and biopsy. High immunosuppressive drug levels, although minimizing rejection, are related to significant side effects such as nephrotoxicity and metabolic syndrome, contributing to long-term morbidity and mortality. Similarly, levels that are lower than necessary can decrease the rate of side effects with a potential toll on rejection and graft survival. Herein, the authors present an update on immunosuppressive drug level monitoring and manipulation strategies according to different scenarios and time from transplant. They also provide a brief overview of next level immunosuppression monitoring strategies that aim to properly balance rejection rates with drug side effect profiles.
\end{abstract}

Prevention of liver allograft rejection in the immediate and late postorthotopic liver transplant (OLT) period involves the simultaneous use of multiple different classes of immunosuppressive medications. T cell-mediated rejection, which is responsible for the vast majority of rejection episodes, ${ }^{1}$ is the result of a multistep process initiated by antigen presenting cells leading to $\mathrm{T}$ cell activation, autostimulation, proliferation, and transendothelial migration leading to alloantigen tissue injury. ${ }^{2}$ Each step on this chain of events is mediated by specific cells, receptors, and cytokines that can be purposely targeted by various classes of immunosuppressive medications.

Assuming appropriate immunosuppressant tissue levels, rejection can be prevented in the majority of patients. Measurement of direct tissue concentrations is not possible in clinical practice although it can be inferred from circulating drug levels. On the other hand, circulating blood levels are a function of dosage, frequency of dosing, route of administration, and drug metabolism and excretion primarily through the liver and kidneys. It is important to note that, although serum/whole blood medication levels can correlate well with tissue levels, they are only one piece of the puzzle to ascertain the risk of rejection. Several clinical and biochemical factors need to be monitored to ensure proper allograft immune tolerance and function. More specifically, liver biochemistries have been classically monitored to alert for possible liver injury. It is possible that, in individual cases, lower than recommended immunosuppression levels might be enough for adequate allograft immune tolerance. It is thus still important to rely on clinical day-to-day operations and individualize medication decisions while keeping with the most recent guidelines.

The triple immunosuppressive regimen of steroids, tacrolimus (TAC), and antimetabolites is the preferred immediate posttransplant combination in the United States. ${ }^{3}$ Drug level monitoring is more intense during the immediate posttransplant period, as the risk of rejection is highest during the first few weeks. There are no strict guidelines directing immunosuppressive care, and there are significant interinstitutional differences in medication protocols. Although modern agents are effective in the prevention of liver allograft rejection, they also cause significant side effects dependent on dose and duration. Manipulation of drug levels can have a favorable impact on several side effects and adverse events related to published online April 30, 2019
Copyright $\odot 2019$ by Thieme Medical Publishers, Inc., 333 Seventh Avenue, New York, NY 10001, USA. Tel: +1(212) 584-4662.
DOI https://doi.org/ 10.1055/s-0039-1688443. ISSN 0272-8087. 
Table 1 Proactive therapeutic drug level monitoring of $\mathrm{CNIs}^{\mathrm{a}, \mathrm{b}}$

\begin{tabular}{|c|c|c|c|c|c|}
\hline Agent & Period & $\begin{array}{l}\text { Suggested dose } \\
\text { without renal } \\
\text { impairment }\end{array}$ & $\begin{array}{l}\text { Suggested dose adjustment with renal } \\
\text { impairment during therapy }\end{array}$ & $\begin{array}{l}\text { Frequency } \\
\text { of level } \\
\text { monitoring }\end{array}$ & $\begin{array}{l}\text { Target C0 } \\
\text { levels }^{c}\end{array}$ \\
\hline \multirow[t]{4}{*}{ Cyclosporine } & $\begin{array}{l}\text { Immediately } \\
\text { posttransplant } \\
\text { until discharge }\end{array}$ & $\begin{array}{l}8 \pm 4 \mathrm{mg} / \mathrm{kg} / \mathrm{d} \text { in } \\
2 \text { divided doses }\end{array}$ & $\begin{array}{l}\text { Creatinine increase } \geq 25 \% \text { : Lower dose } \\
25-50 \% \\
\text { Creatinine increase } \geq 50 \% \text { : Lower dose } \\
25-50 \% \text { or discontinue if undesirable levels }\end{array}$ & Daily & $200-250 \mathrm{ng} / \mathrm{mL}$ \\
\hline & $\begin{array}{l}\text { Postdischarge } \\
\text { to } 3 \text { mo }\end{array}$ & Same & Same & $\begin{array}{l}\text { Weekly to } \\
\text { biweekly }\end{array}$ & $150-200 \mathrm{ng} / \mathrm{mL}$ \\
\hline & $3-12 \mathrm{mo}$ & Same & Same & Every $1-2$ mo & $100-150 \mathrm{ng} / \mathrm{mL}$ \\
\hline & $>12 \mathrm{mo}$ & Same & Same & $\begin{array}{l}\text { At least every } \\
6 \text { mo }\end{array}$ & $\leq 100 \mathrm{ng} / \mathrm{mL}$ \\
\hline \multirow[t]{4}{*}{ Tacrolimus } & $\begin{array}{l}\text { Immediately } \\
\text { posttransplant } \\
\text { to discharge }\end{array}$ & $\begin{array}{l}0.1-0.15 \mathrm{mg} / \mathrm{kg} / \mathrm{d} \\
\text { in } 2 \text { divided doses }\end{array}$ & $\begin{array}{l}\text { Consider lower dosing while closely } \\
\text { monitoring creatinine }\end{array}$ & Daily & $7-10 \mathrm{ng} / \mathrm{mL}$ \\
\hline & $\begin{array}{l}\text { Postdischarge } \\
\text { to } 3 \mathrm{mo}\end{array}$ & Same & Individualized according to desired levels & $\begin{array}{l}\text { Weekly to } \\
\text { biweekly }\end{array}$ & $7-10 \mathrm{ng} / \mathrm{mL}$ \\
\hline & After 3 mo & Same & Individualized according to desired levels & Every $1-2$ mo & $6-10 \mathrm{ng} / \mathrm{mL}$ \\
\hline & After 12 mo & Same & Individualized according to desired levels & Every $6 \mathrm{mo}$ & $\leq 5 \mathrm{ng} / \mathrm{mL}$ \\
\hline
\end{tabular}

Abbreviation: CNI, calcineurin Inhibitor.

${ }^{\mathrm{a}}$ Assuming a clinical, laboratory, and histological response, and absence of drug-drug interactions. ${ }^{\mathrm{b}}$ Cyclosporine dosing is twice daily. Tacrolimus dosing is twice daily.

'Whole blood measured 12 hours after the last dose (trough levels).

immune compromise, such as malignancy and infections. It is paramount that immunosuppression is handled by experts in transplantation, as there has been no marker that aids in identifying a truly effective level of immunosuppression. ${ }^{4}$ It is also increasingly recognized that transplant pharmacist consultation might improve the quality of care among liver transplant recipients. ${ }^{5}$ It is critical to note drug levels can vary significantly not only between patients but also within the same patient over time; risk factors for these changes are numerous but mainly have to do with the use of different assays (more modern assays have been considerably more sensitive and reliable over time, such as high-performance liquid chromatography-linked tandem mass spectrometry), timing of dose, and drug-to-drug interactions. ${ }^{6}$

Our goal with this review is to provide an updated summary on modern immunosuppressive drug level monitoring and manipulation in the early and late post OLT period ( - Table $\mathbf{1}$,

- Fig. 1, on selective strategies on immunosuppression management; - Table 2, on important drug-drug interactions; and - Table 3, on specific recommendations regarding different clinical scenarios in liver transplantation), thus aiding in the proper balancing of benefit and side effects. We also provide a summary of future directions in drug level and immune monitoring in the setting of liver transplantation.

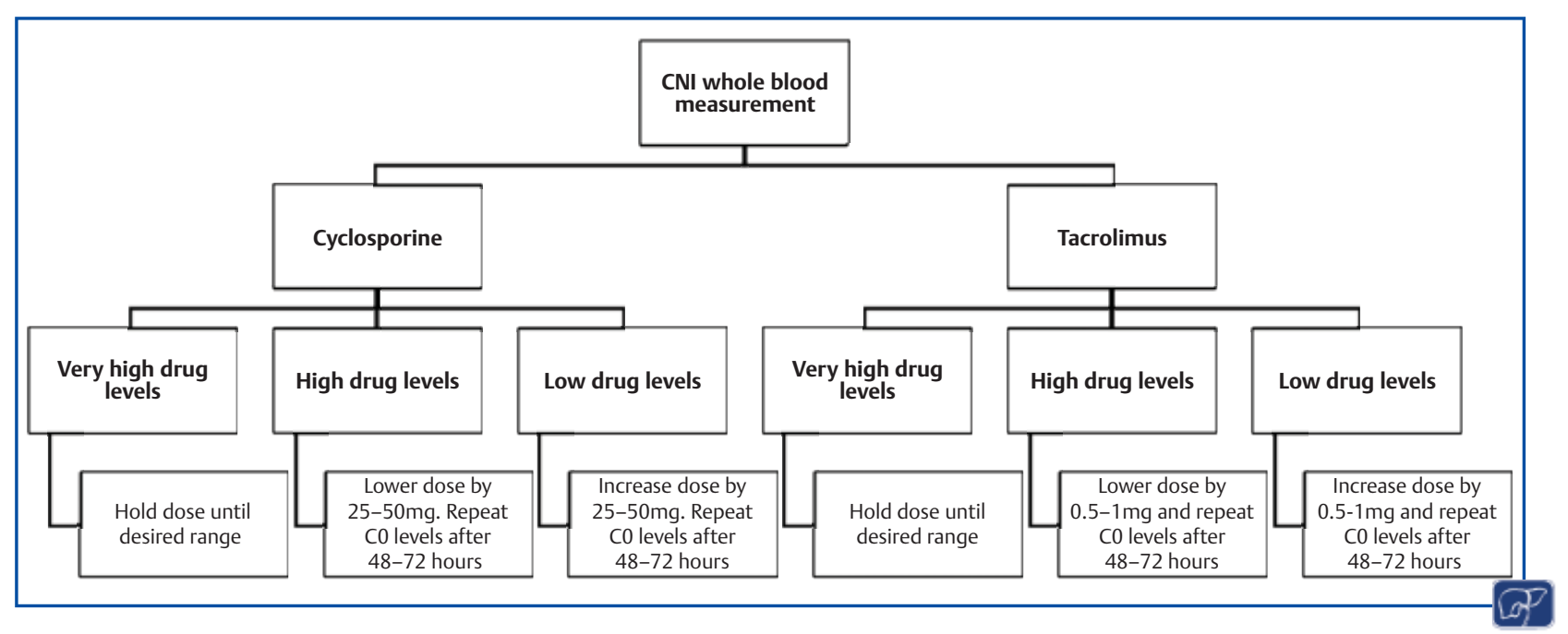

Fig. 1 Dosing strategies for steady-state ${ }^{a}$ trough CNI-level manipulation. ${ }^{\text {b }}$ Steady-state concentrations are reached after $4-6$ doses. ${ }^{b}$ Assuming correct and timely measurement 
Table 2 Important drug-drug interactions of calcineurin inhibitors, and mechanistic target of rapamycin inhibitors

\begin{tabular}{|c|c|c|}
\hline Drug & $\begin{array}{l}\text { Effect on } \\
\text { drug level }\end{array}$ & Dosing action needed ${ }^{a}$ \\
\hline $\begin{array}{l}\text { Oral } D A A^{b}-3 D \\
\text { regimen }\end{array}$ & $\begin{array}{l}\uparrow T A C^{d} \\
\uparrow C y s^{e}\end{array}$ & $\begin{array}{l}\text { Decrease dose to } \\
0.5 \text { mg once every } 7 \mathrm{~d} \\
\text { Decrease daily dose to } \\
1 / 5 \text { of total previous } \\
\text { daily dose }\end{array}$ \\
\hline Boceprevir $^{44}$ & $\begin{array}{l}\uparrow T A C \\
\uparrow C y s\end{array}$ & $\begin{array}{l}\text { Decrease dose } 5 \text {-fold } \\
\text { Decrease dose } 2 \text {-fold }\end{array}$ \\
\hline Telaprevir & $\begin{array}{l}\uparrow T A C \\
\uparrow C y s\end{array}$ & $\begin{array}{l}\text { Decrease dose } 35 \text {-fold } \\
\text { Decrease dose } 4 \text {-fold }\end{array}$ \\
\hline Sofosbuvir & No change & No change \\
\hline Daclatasvir & No change & No change \\
\hline Protease inhibitors & $\begin{array}{l}\uparrow \text { Cys } \\
\uparrow T A C \\
\uparrow \mathrm{mTORi}^{\mathrm{f}}\end{array}$ & Decrease dose \\
\hline $\begin{array}{l}\text { Nondihydropyridine } \\
\text { calcium } \\
\text { channel blockers }\end{array}$ & $\begin{array}{l}\uparrow \text { Cys } \\
\uparrow \mathrm{TAC} \\
\uparrow \mathrm{mTORi}\end{array}$ & Same \\
\hline $\begin{array}{l}\text { Azole antifungal } \\
\text { agents }\end{array}$ & $\begin{array}{l}\uparrow \text { Cys } \\
\uparrow T A C \\
\uparrow \mathrm{MTORi}\end{array}$ & Same \\
\hline $\begin{array}{l}\text { Macrolides } \\
\text { (except } \\
\text { azithromycin) }\end{array}$ & $\begin{array}{l}\uparrow \text { Cys } \\
\uparrow \mathrm{TAC} \\
\uparrow \mathrm{mTORi}\end{array}$ & Same \\
\hline Cobicistat & $\begin{array}{l}\uparrow \text { Cys } \\
\uparrow T A C \\
\uparrow \mathrm{mTORi}\end{array}$ & Decrease dose \\
\hline $\begin{array}{l}\text { Carbamazepine } \\
\text { Phenytoin } \\
\text { Primidone }\end{array}$ & $\begin{array}{l}\downarrow \text { Cys } \\
\downarrow \text { TAC } \\
\downarrow \text { mTORi }\end{array}$ & Same \\
\hline Rifamycins & $\begin{array}{l}\downarrow \text { Cys } \\
\downarrow \text { TAC } \\
\downarrow \text { mTORi }\end{array}$ & Same \\
\hline
\end{tabular}

${ }^{\text {a }}$ Standard level monitoring frequency should be 3-4 days after initiation of change.

${ }^{\mathrm{b}}$ Direct acting antiviral agents.

'Combination of dasabuvir, daclatasvir, and ombitasvir.

${ }^{\mathrm{d}}$ Tacrolimus.

${ }^{\mathrm{e} C y c l o s p o r i n e .}$

${ }^{\mathrm{f}}$ Mechanistic target of rapamycin inhibitors.

\section{Calcineurin Inhibitors}

The need for T-lymphocyte inhibition to improve allograft outcomes was recognized early in the 1970s with clinicians relying on the use of steroids, azathioprine (AZA), and thoracic duct drainage, which had low efficacy. ${ }^{7}$ Calcineurin inhibitors (CNIs) revolutionized the field of liver transplantation in the 1980s by preventing rejection in the majority and are used as standard-of-care to this day. These medications are mainly metabolized through the cytochrome P4503A (CYP4503A) and have a narrow therapeutic index. Significant side effects include nephrotoxicity, neurotoxicity, and metabolic syndrome. ${ }^{1,8}$ Both available CNIs (TAC and cyclosporine) require whole-blood level measurements as the majority is concentrated in erythrocytes. ${ }^{9}$

\section{Cyclosporine}

Cyclosporine is a natural fungal protein, with its main immunosuppressive effect being the reduction of interleukin (IL)$2 .^{10}$ By the end of the 1970 s, Borel et $\mathrm{al}^{11}$ and Calne et $\mathrm{al}^{12}$ showed the potent immunosuppressive effect of cyclosporine$A$ in rodent and human liver allograft survival, respectively. During the 1980s, the use of cyclosporine-A rose exponentially despite side effects as well as erratic gastrointestinal absorption given its codependence on bile acids. Its new formulation in the 1990s improved its absorption and side effect profile.

However, over the last two decades, cyclosporine has been mainly replaced by its more potent alternative TAC. Cyclosporine can be the initial preferred treatment among patients who do not tolerate TAC, such as those with significant neurotoxicity, hemolytic-uremic syndrome, or poor glucose control. ${ }^{4}$ Also, recent data suggest that cyclosporine might be a superior agent than TAC in the prevention of primary biliary cholangitis recurrence (hazard ratio, $0.62, p$-value $=0.001$ ), and, while debatable, could be preferred in this subset of patients. ${ }^{13}$

-Table 1 and -Fig. 1 display therapeutic drug level monitoring and manipulation strategies. Cyclosporine oral dosing typically starts on day-1 posttransplant, and intravenous or liquid formulations are used among patients unable to tolerate oral administration. Levels are typically checked either 12 hours after the last oral dose (trough) (C0), or 2 hours after the last dose (C2). The choice of monitoring is institution-dependent with the most popular method being the C0 method. Trough levels are more convenient for patients; however, there are some data to support a better correlation between C2 monitoring and cyclosporine level AUC of 0 to 4 hours compared with $\mathrm{C} 0 .^{14}$

It is evident that different CYP450 alleles might significantly affect the rate of circulating cyclosporine levels; however, genetic profiling of liver transplant recipients is not routinely part of current guidelines. Data suggest that CYP3A $4^{*} 1 \mathrm{~B}^{15}$ or CYP $3 A 5^{*} 1^{16}$ carriers might require lower and higher doses of cyclosporine, respectively, to reach steady-state concentrations, although these studies have mainly been performed in renal transplant recipients. Genetic polymorphisms of CYP3A5 have also been related to decreased levels of circulating TAC. Also, intravenous dosing has been shown to be superior to oral dosing in achieving early effective levels of the drug in the immediate postoperative period in patients with genetic polymorphisms such as CYP3A5 $3 .{ }^{17}$ Importantly, genetic polymorphisms of CYP3A5 can be different between ethnic groups which can lead to either a high or low drug metabolism rate. More specifically, the allele of CYPEA $5 * 3$ is more frequent in Caucasian Canadians, than Zimbabweans, and CYP3A5*6 and 7 are more frequent in African individuals and absent in Caucasian. ${ }^{18}$ More studies are needed in the epidemiology of CYP genetic polymorphisms and immunosuppressant metabolism to see whether such information could translate in guidelines requiring genetic profiling prior to initiation of therapy in the transplant population.

\section{Tacrolimus}

Tacrolimus or FK506 is a bacterial macrolide lactone produced by Streptomyces tsukubaensis. In 1987, Todo et al first reviewed 
Table 3 Relationship of drug concentrations and side effects in different settings of liver transplantation and recommendations for action

\begin{tabular}{|c|c|c|}
\hline \multirow[t]{2}{*}{ Clinical Scenario } & \multicolumn{2}{|l|}{ Recommendations } \\
\hline & Too high immunosuppression level & Too low immunosuppression level \\
\hline \multirow[t]{2}{*}{$\begin{array}{l}\text { Renal dysfunction } \\
\text { posttransplantation }\end{array}$} & $\begin{array}{l}\text { Lower dose at a higher rate than normal } \\
\text { individuals }\end{array}$ & $\begin{array}{l}\text { Increase dose sparingly. If long time after } \\
\mathrm{OLT}^{\mathrm{a}} \text { may consider maintaining that level if no } \\
\text { biochemical or tissue sign of rejection }\end{array}$ \\
\hline & \multicolumn{2}{|c|}{$\begin{array}{l}\text { Consider } \mathrm{CNI}^{\mathrm{b}} \text { sparing agent like } \mathrm{MMF}^{\mathrm{c}} \text { or } \mathrm{mTORi}^{\mathrm{d}}+\text { intensify level monitoring until steady- } \\
\text { state is reached }\end{array}$} \\
\hline \multirow[t]{2}{*}{ Metabolic syndrome } & $\begin{array}{l}\text { Standard lowering of dose for overweight/ } \\
\text { obese same as lean individuals }\end{array}$ & $\begin{array}{l}\text { Standard increase of dose for overweight/ } \\
\text { obese same as lean individuals }\end{array}$ \\
\hline & \multicolumn{2}{|c|}{$\begin{array}{l}\text { Consider CNI sparing agent like MMF or mTORi }\left(\text { TAC }^{\mathrm{e}} \text { preferable than } \mathrm{Cys}^{\mathrm{f}}\right)+\text { level monitoring } \\
\text { more frequent until steady-state is reached }\end{array}$} \\
\hline \multirow[t]{2}{*}{ Diabetes } & Standard lowering of dose & Standard increase of dose \\
\hline & \multicolumn{2}{|c|}{$\begin{array}{l}\text { Consider CNI sparing agent like MMF or mTORi }+ \text { TAC linked to higher incidence of diabetes, } \\
\text { but still better outcomes than Cys. Levels should be kept at the absolute minimum with CNI } \\
\text { sparing agents }\end{array}$} \\
\hline \multirow[t]{2}{*}{ Hepatocellular carcinoma } & Standard lowering of dose & Standard increase of dose \\
\hline & \multicolumn{2}{|c|}{$\begin{array}{l}\text { Intensify level monitoring until steady-state is reached }+ \text { debatable advantage for sirolimus } \\
\text { use }\end{array}$} \\
\hline \multirow[t]{2}{*}{ Cholangiocarcinoma } & Standard lowering of dose & Standard increase of dose \\
\hline & \multicolumn{2}{|c|}{ Intensify level monitoring until steady-state is reached + debatable advantage of mTORi } \\
\hline \multirow[t]{2}{*}{$\begin{array}{l}\text { History of cancer } \\
\text { prior to transplant }\end{array}$} & Standard lowering of dose & Standard increase of dose \\
\hline & \multicolumn{2}{|c|}{$\begin{array}{l}\text { Intensify level monitoring until steady-state is reached }+ \text { if recurrence might consider } \\
\text { switching to mTORi }\end{array}$} \\
\hline \multirow[t]{2}{*}{$\begin{array}{l}\text { De novo cancer } \\
\text { posttransplantation }\end{array}$} & Standard lowering of dose & Standard increase of dose \\
\hline & \multicolumn{2}{|c|}{ Minimize immunosuppression according to histologic and biochemical profile } \\
\hline \multirow[t]{2}{*}{ Pregnancy } & Standard lowering of dose & Standard increase of dose \\
\hline & \multicolumn{2}{|c|}{$\begin{array}{l}\text { Consider intensification of immunosuppression monitoring in the peripartum period which } \\
\text { involves rapid shifts in the circulating volume of distribution. Avoid Azathioprine and MMF as } \\
\text { they are FDA } \text { Fategory D }^{g} \text { as }\end{array}$} \\
\hline \multirow[t]{2}{*}{ Adolescents } & $\begin{array}{l}\text { Standard lowering of dose }+ \text { prefer once } \\
\text { daily dosing }\end{array}$ & $\begin{array}{l}\text { Standard increase of dose }+ \text { prefer once daily } \\
\text { dosing }\end{array}$ \\
\hline & \multicolumn{2}{|c|}{$\begin{array}{l}\text { Transition to adolescence is accompanied by change in drug pharmacokinetics and pharma- } \\
\text { codynamics (children require higher doses typically). Consider intensification of level mon- } \\
\text { itoring during this period }\end{array}$} \\
\hline Poor medication adherence & $\begin{array}{l}\text { Standard lowering of dose }+ \text { prefer once } \\
\text { daily dosing }\end{array}$ & $\begin{array}{l}\text { Standard increase of dose }+ \text { prefer once daily } \\
\text { dosing }\end{array}$ \\
\hline
\end{tabular}

${ }^{a}$ Orthotopic liver transplantation.

${ }^{\mathrm{b}}$ Calcineurin inhibitors.

${ }^{c}$ Mycophenolate mofetil.

${ }^{\mathrm{d}}$ Mechanistic target of rapamycin inhibitors.

${ }^{\mathrm{e}}$ Tacrolimus.

${ }^{\mathrm{f}}$ Cyclosporine.

${ }^{9}$ Food and Drug Administration.

its efficacy in canine liver transplantation. ${ }^{19}$ Its first use in human liver transplantation was reported by Starzl et al in $1989,{ }^{20}$ and since the mid-1990s, TAC is the preferred immunosuppressive agent due to its higher potency and more stable pharmacokinetics compared with cyclosporine. ${ }^{21,22}$ Its mode of action is the same as with cyclosporine reducing IL-2 levels and preventing acute and chronic rejection. It is mainly metabolized by the liver. Kidney dysfunction does not affect TAC drug levels, although high levels can lead to nephrotoxicity due to acute and chronic vasoconstriction. Obesity does not influence target TAC trough levels. ${ }^{23}$

Although there are two TAC formulations available-one that permits once-daily dosing (extended release) and one that depends on twice-per-day dosing (immediate-release)- 
only immediate-release capsules are currently officially approved in the United States for use among liver transplant recipients. A post-hoc analysis showed that mortality was $10 \%$ higher among female recipients receiving extendedrelease versus immediate-release TAC. $^{24}$ On the other hand, medication nonadherence can reach 50\% among transplant recipients and can be related to dosing frequency. ${ }^{25}$ Once-daily dosing has been linked to higher medication adherence and has proven equally effective in patients converted from twice- to once-daily TAC. ${ }^{26}$ It is important to note that once-daily regimens might need to be avoided during the induction phase of immunosuppression as they have been linked to suboptimal levels. ${ }^{27,28}$

-Table 1 and - Fig. 1 also display therapeutic drug level monitoring and manipulation recommendations for TAC. Clinicians should aim for a target trough of 7 to $10 \mathrm{ng} / \mathrm{mL}$ early in the immediate posttransplantation period as it has been shown that those who achieve a level of $>7 \mathrm{ng} / \mathrm{mL}$ might have a lower risk of cellular rejection ( $23.8 \%$ vs. $41.2 \%)$ as well as better long-term graft survival. ${ }^{29}$ Higher TAC levels (10-15 $\mathrm{ng} / \mathrm{mL}$ ) are not more beneficial and can lead to nephrotoxicity and higher mortality (particularly with levels $>20 \mathrm{ng} / \mathrm{mL}$ ). ${ }^{29}$ Long-term, perhaps after 1 year, lower TAC levels $(<5 \mathrm{ng} / \mathrm{mL})$ are effective in minimizing rejection and optimizing graft function. ${ }^{30}$ In pregnancy, TAC levels should be kept similar as in nonpregnant patients, although there has been significant variability among studies. ${ }^{31}$ We recommend more frequent monitoring during the peripartum period with appropriate dosing adjustments to avoid rejection or nephrotoxicity.

\section{Overview of Drug-CNI Interactions}

Both TAC and cyclosporine rely on CYP4503A4 and P-glycoprotein pump (Pgp) for their metabolism and excretion. Various nonimmunosuppressive medications can either induce or inhibit CYP4503A and/or Pgp leading to critical decreases or increases in CNI levels, respectively. Clinicians need to be aware of these interactions and ensure appropriate drug level monitoring to avoid allograft rejection or adverse effects. Importantly, CNI dosage adjustments might be needed among posttransplant recipients receiving directacting antiretroviral agents, highly active antiretroviral therapy, calcium channel blockers, macrolide antibiotics, azole antifungal agents, seizure drugs, and rifampicin derivatives. Refer to - Table 2 for a brief overview of clinically significant interactions between CNIs and P4503A altering medications. Also, patients on statins might experience an increase in levels after CNI commencement. Typically, cyclosporine and simvastatin should not be used in combination, and fluvastatin or pravastatin are preferred statins used in patients on CNIs.

\section{Mechanistic Target of Rapamycin Inhibitors}

The first mechanistic target of rapamycin (mTOR) inhibitor, sirolimus, was approved by the Food and Drug Administration (FDA) in 1999 and everolimus was approved in 2013; both have been mainly used in as CNI sparing agents partly due to their absent nephrotoxicity. ${ }^{32}$ Sirolimus has black-box FDA warnings on the risk of hepatic artery thrombosis if used within the first 30 days posttransplant and excess mortality if combined with TAC. Both sirolimus and everolimus are measured in whole blood as they can concentrate within red blood cells. The half-life of sirolimus is significantly longer than everolimus (57-63 hours vs. 30 hours) permitting oncedaily maintenance dosing compared with twice daily. Sirolimus is given orally at a dose of 1 to $5 \mathrm{mg}$ daily. Sirolimus could be considered in patients with hepatocellular carcinoma due to its proposed antiproliferative properties; however, there is no compelling evidence to recommend translation of this knowledge to the bedside. Levels of sirolimus have not been found to correlate well with liver allograft rejection hence they are not currently measured by most centers. ${ }^{35}$

Everolimus is a sirolimus chemical derivative and has a similar mechanism of action. It is dosed at $0.75 \mathrm{mg}$ twicedaily with target levels of 3 to $8 \mathrm{ng} / \mathrm{mL}$ and is approved for use in liver transplant recipients in combination with TAC (goal: 3-5 ng/mL) after 30 days. Dosing of mTOR inhibitors might need to be adjusted if combined with P4503A and/or Pgp inducers or inhibitors (see - Table $\mathbf{2}$ for more information). The use of the combination of protease inhibitors in HIV positive recipients, nondihydropyridine calcium channel blockers, azole antifungal agents, or macrolide antibiotics (except azithromycin) leads to increased levels of mTOR inhibitors warranting a lower dose. The reverse is true for certain antiepileptic medications and rifamycins, which promptly lower circulating levels of mTOR inhibitors.

\section{Nucleotide Synthesis Inhibitors}

\section{Mycophenolate Mofetil}

Mycophenolate mofetil (MMF) or mycophenolic acid exerts its effects by inhibiting the synthesis of nucleotide guanine triphosphate. In transplantation, MMF inhibits the proliferation of activated lymphocytes and is superior to AZA in preventing rejection. It is considered a steroid-sparing and $\mathrm{CNI}$-sparing agent given the absence of neuro- or nephrotoxicity. It can, however, have gastrointestinal side effects such as diarrhea, abdominal pain, and nausea, which can hinder the dosage of other oral medications, as well as bonemarrow toxicity. The usual dose is $1 \mathrm{~g}$ twice-daily and levels are not routinely performed given the weak correlation with MMF area under the curve (AUC). Interestingly, one study showed that high intrapatient MMF variability of $>35 \%$ and trough levels of $<5 \mathrm{ng} / \mathrm{mL}$ were linked to increased risk of acute rejection and formation of de novo donor-specific antibodies. ${ }^{36}$ Also, a retrospective examination of events 3 days before rejection showed that patients who had rejection had MMF levels of $<2 \mathrm{ng} / \mathrm{mL}^{37}$ Larger prospective observational studies are needed to establish safe and effective MMF levels among liver transplant recipients.

\section{Azathioprine}

Azathioprine is a purine analog that incorporates into deoxyribonucleic acid and inhibits cell replication, thus 
preventing the expansion of activated $\mathrm{T}$ and $\mathrm{B}$ lymphocytes. AZA is not commonly used in clinical transplant practice except perhaps in patients transplanted for autoimmune hepatitis. It is frequently dosed at 1.5 to $2 \mathrm{mg} / \mathrm{kg} /$ day. Direct AZA levels are not useful to predict transplant or side effect outcomes. Instead, thiopurine S-methyltransferase genotype and/or enzyme activity is checked before initiation of therapy to avoid toxicity; as an adjunct, both AZA metabolites-6thioguanine and 6-methylmercaptopurine-can also be measured systemically as surrogates of AZA metabolism. ${ }^{38}$

\section{Antibody Therapy}

Steroids and CNIs are the most commonly used induction agents after OLT; however, some recipients experience steroid-resistant rejection or are heavily intolerant of CNIs. In this situation, antibody therapy can become extremely useful. Polyclonal antibodies such as antithymocyte globulin and antilymphocyte globulin and monoclonal antibodies are not as commonly used and most centers prefer the use of monoclonal antibodies such as muromonab-CD3 (OKT3), at an intravenous dose of $5 \mathrm{mg}$ daily for up to 2 weeks and the less immunogenic agent basiliximab and daclizumab (the latter is not available in the United States).

\section{Management of Immunosuppression in Liver-Kidney Allograft Recipients}

The number of simultaneous liver-kidney transplant (SLKT) recipients is steadily rising mainly because pre-OLT kidney dysfunction has been predictive of post-OLT renal failure and worse outcomes. $^{39}$ The number of SLKT procedures in the United States has risen from around 200 in 2000 up to around 720 in $2016 .^{39}$ This, of course, has led to unique challenges with immunosuppression management given that TAC and cyclosporine-two of the most popular induction agents in single organ liver transplant recipients-can be nephrotoxic. According to the United Network for Organ Sharing (UNOS), from 2002 to 2016, around 90\% of SLKT cases in the United States used TAC as a maintenance regimen at the time of discharge and almost all centers avoided CNIs during induction. ${ }^{40}$ Immediately posttransplant, most centers induce immunosuppression via rabbit antithymocyte immunoglobulin ( $\mathrm{r}$ ATG) or IL2 receptor antagonists (IL2RA) and later transition to a combination of CNIs with MMF. However, the benefit of induction regimens in SLKT has been challenged recently by a retrospective 15-year analysis of SLKT data in UNOS database, which looked at the long-term outcomes of all adult combined transplant recipients who were maintained with TAC and $\mathrm{MMF}^{40}$ In this analysis, the study population was stratified in three groups according to a separate induction strategy ( $r$ ATG, IL2RA, and no induction) and found that use of r-ATG was associated with increased all-cause mortality, and that no induction overall appeared beneficial. Unfortunately, there are no guidelines on specific immunosuppressive medication levels in the SLKT scenario, and most clinicians rely on expert opinion or derive their management from experience with OLT patients who suffer from chronic kidney dysfunction. This is important because excessive immunosuppression has been found to be a cause of poor survival in SLKT recipients. ${ }^{41}$ We recommend avoidance of CNIs during the induction period and encourage the subsequent use of TAC combined with MMF to ensure the absolute least TAC dosing. Levels of TAC should be individualized according to each clinical scenario; however, they should not exceed the current recommended upper levels (readers are advised to review - Table $\mathbf{1}$ for target levels in patients with chronic kidney dysfunction for both TAC and cyclosporine).

\section{Future Directions}

Currently, clinicians are alerted on potential rejection based on liver enzyme monitoring and liver biopsies. There is no accepted test that can predict this rejection and tailoring of immunosuppressant drug levels relies on trial and error. ${ }^{42}$ Emerging evidence suggest that monitoring of the immune components responsible for rejection (also known as immune monitoring), such as $\mathrm{T}$ lymphocytes and their cytokines, might provide insights into immunosuppressive strategies. ${ }^{42}$ This monitoring aims in deciding whether the transplant recipient has developed tolerance toward the foreign allogeneic transplant. Unfortunately, there are significant interlaboratory variations, and coordinated efforts such as Minimal Information About T cell Assays have been made to standardize the quality of immune monitoring. ${ }^{43}$ The goal is to develop an immune monitoring assay that is cheap, fast, and precise providing valid information regarding the net-immunosuppressive state of the transplant recipient. This strategy should be able to aid clinicians to titrate medications according to impending rejection and toxic side effects and ultimately select candidates for complete immunosuppression withdrawal.

\section{Main Concepts and Learning Points}

- Immunosuppressive drug level monitoring, in combination with liver enzymes, and liver biopsies are the only means of assessing rejection, and no accepted test can predict it.

- Too high or low immunosuppressive drug levels are associated with significant side effects and rejection, respectively, and need to be corrected promptly.

- Calcineurin inhibitors are the category of drugs that represent the standard of care for primary immunosuppression in liver transplant recipients and are closely monitored in the posttransplantation period.

- Calcineurin inhibitor and mechanistic target of rapamycin inhibitor levels are affected by P450-altering medications and require intense drug level monitoring and adjustment.

- Immune monitoring is a promising field of transplant hepatology that aims to prevent rejection episodes through the assessment of immune activation versus tolerance leading to preemptive immunosuppressive drug adjustments.

Conflict of Interest

None. 


\section{References}

1 Charlton M, Levitsky J, Aqel B, et al. International Liver Transplantation Society consensus statement on immunosuppression in liver transplant recipients. Transplantation 2018;102(05):727-743

2 Yokota S, Yoshida O, Ono Y, Geller DA, Thomson AW. Liver transplantation in the mouse: Insights into liver immunobiology, tissue injury, and allograft tolerance. Liver Transpl 2016;22(04): 536-546

3 Nazzal M, Lentine KL, Naik AS, et al. Center-driven and clinically driven variation in US liver transplant maintenance immunosuppression therapy: a national practice patterns analysis. Transplant Direct 2018;4(07):e364

4 Lucey MR, Terrault N, Ojo L, et al. Long-term management of the successful adult liver transplant: 2012 practice guideline by the American Association for the Study of Liver Diseases and the American Society of Transplantation. Liver Transpl 2013;19(01): 3-26

5 Schuh MJ, Massoglia G. Pharmacist impact on tacrolimus serum concentrations in liver transplant patients. Consult Pharm 2018; 33(05):268-272

6 Shuker N, van Gelder T, Hesselink DA. Intra-patient variability in tacrolimus exposure: causes, consequences for clinical management. Transplant Rev (Orlando) 2015;29(02):78-84

7 Starzl TE, Weil R III, Iwatsuki S, et al. The use of cyclosporin A and prednisone in cadaver kidney transplantation. Surg Gynecol Obstet 1980;151(01):17-26

8 Pflugrad H, Schrader AK, Tryc AB, et al. Long-term calcineurin inhibitor therapy and brain function in patients after liver transplantation. Liver Transpl 2018;24(01):56-66

9 Nagase K, Iwasaki K, Nozaki K, Noda K. Distribution and protein binding of FK506, a potent immunosuppressive macrolide lactone, in human blood and its uptake by erythrocytes. J Pharm Pharmacol 1994;46(02):113-117

10 Hess AD, Colombani PM. Mechanism of action of cyclosporine: role of calmodulin, cyclophilin, and other cyclosporine-binding proteins. Transplant Proc 1986;18(06, Suppl 5):219-237

11 Borel JF, Feurer C, Magnée C, Stähelin H. Effects of the new antilymphocytic peptide cyclosporin A in animals. Immunology 1977;32(06):1017-1025

12 Calne RY, Rolles K, White DJ, et al. Cyclosporin A initially as the only immunosuppressant in 34 recipients of cadaveric organs: $32 \mathrm{kid}-$ neys, 2 pancreases, and 2 livers. Lancet 1979;2(8151):1033-1036

13 Montano-Loza AJ, Hansen BE, Corpechot C, et al. Global PBC Study Group. Factors associated with recurrence of primary biliary cholangitis after liver transplantation and effects on graft and patient survival. Gastroenterology 2019;156(01):96-107.e1

14 Cantarovich M, Barkun JS, Tchervenkov JI, Besner JG, Aspeslet L, Metrakos P. Comparison of neoral dose monitoring with cyclosporine through levels versus 2-hr postdose levels in stable liver transplant patients. Transplantation 1998;66(12):1621-1627

15 Wang CE, Lu KP, Chang Z, Guo ML, Qiao HL. Association of CYP3A4*1B genotype with Cyclosporin A pharmacokinetics in renal transplant recipients: a meta-analysis. Gene 2018;664:44-49

16 Żochowska D, Wyzgał J, Pączek L. Impact of CYP3A4*1B and CYP3A $5 * 3$ polymorphisms on the pharmacokinetics of cyclosporine and sirolimus in renal transplant recipients. Ann Transplant 2012;17(03):36-44

17 Kato $\mathrm{H}$, Usui M, Muraki $\mathrm{Y}$, et al. Intravenous administration of tacrolimus stabilizes control of blood concentration regardless of CYP3A5 polymorphism in living donor liver transplantation: comparison of intravenous infusion and oral administration in early postoperative period. Transplant Proc 2018;50(09):2684-2689

18 Roy JN, Lajoie J, Zijenah LS, et al. CYP3A5 genetic polymorphisms in different ethnic populations. Drug Metab Dispos 2005;33(07): 884-887

19 Todo S, Podesta L, ChapChap P, et al. Orthotopic liver transplantation in dogs receiving FK-506. Transplant Proc 1987;19(05, Suppl 6):64-67
20 Starzl TE, Todo S, Fung J, Demetris AJ, Venkataramman R, Jain A. FK 506 for liver, kidney, and pancreas transplantation. Lancet 1989;2 (8670):1000-1004

21 Group USMFLS; U.S. Multicenter FK506 Liver Study Group. A comparison of tacrolimus (FK 506) and cyclosporine for immunosuppression in liver transplantation. N Engl J Med 1994;331 (17):1110-1115

22 Bismuth H. Comparison of FK 506- and cyclosporine-based immunosuppression: FK 506 therapy significantly reduces the incidence of acute, steroid-resistant, refractory, and chronic rejection whilst possessing a comparable safety profile. European FK 506 Multicenter Liver Study Group. Transplant Proc 1995;27 (01):45-49

23 Liu Z, Cheng J, Powell E, et al. Weight based tacrolimus trough concentrations post liver transplant. Intern Med J 2019;49(01): 79-83

24 Full Prescribing Information of ASTAGRAF XL. Revised December 2015. Available at: https://www.astellas.us/docs/AstagrafXL. pdf. Accessed October 4, 2018

25 Lieber SR, Helcer J, Leven E, et al. Pretransplant psychosocial risk factors may not predict late nonadherence and graft rejection in adult liver transplant recipients. Exp Clin Transplant 2018;16 (05):533-540

26 Lee EC, Kim SH, Park SJ. Safety and efficacy of once-daily prolonged-release tacrolimus in living donor liver transplantation: an open-label, prospective, single-arm, phase 4 study. Ann Transplant 2018;23:713-720

27 Iwasaki M, Yano I, Fukatsu S, et al. Pharmacokinetics and pharmacodynamics of once-daily tacrolimus compared with twicedaily tacrolimus in the early stage after living donor liver transplantation. Ther Drug Monit 2018;40(06):675-681

28 Altieri M, Delaval G, Kimmoun E, Allaire M, Salamé E, Dumortier J. Conversion from once-daily prolonged-release tacrolimus to once-daily extended-release tacrolimus in stable liver transplant recipients. Exp Clin Transplant 2018;16(03):321-325

29 Rodríguez-Perálvarez M, Germani G, Papastergiou V, et al. Early tacrolimus exposure after liver transplantation: relationship with moderate/severe acute rejection and long-term outcome. J Hepatol 2013;58(02):262-270

30 Geng L, Wang LD, Huang JJ, et al. Lower tacrolimus trough levels in the late period after living donor liver transplantation contribute to improvements in long-term clinical outcomes. Hepatobiliary Pancreat Dis Int 2018;17(03):204-209

31 Hebert MF, Zheng S, Hays $\mathrm{K}$, et al. Interpreting tacrolimus concentrations during pregnancy and postpartum. Transplantation 2013;95(07):908-915

32 Kovarik JM, Kaplan B, Silva HT, et al. Pharmacokinetics of an everolimus-cyclosporine immunosuppressive regimen over the first 6 months after kidney transplantation. Am J Transplant 2003; 3(05):606-613

33 Reichen J, Stickel F, Bhattacharya I, Matschke K, Maller E, KorthBradley J. Repeat-dose sirolimus pharmacokinetics and pharmacodynamics in patients with hepatic allografts. Eur J Clin Pharmacol 2012;68(05):589-597

34 Del Bello A, Congy-Jolivet N, Danjoux M, et al. High tacrolimus intra-patient variability is associated with graft rejection, and de novo donor-specific antibodies occurrence after liver transplantation. World J Gastroenterol 2018;24(16):1795-1802

35 Sarvary E, Nemes B, Varga M, et al. Significance of mycophenolate monitoring in liver transplant recipients: toward the cut-off level. Transplant Proc 2012;44(07):2157-2161

36 Coenen MJ, de Jong DJ, van Marrewijk CJ, et al; TOPIC Recruitment Team. Identification of patients with variants in TPMT and dose reduction reduces hematologic events during thiopurine treatment of inflammatory bowel disease. Gastroenterology 2015;149 (04):907-17.e7

37 Miles CD, Westphal S, Liapakis A, Formica R. Simultaneous liver-kidney transplantation: impact on liver transplant patients 
and the kidney transplant waiting list. Curr Transplant Rep 2018; 5(01):1-6

38 AbdulRahim N, Anderson L, Kotla S, et al. Lack of benefit and potential harm of induction therapy in simultaneous liver-kidney transplants. Liver Transpl 2019;25(03):411-424

39 Hibi T, Nishida S, Sageshima J, et al. Excessive immunosuppression as a potential cause of poor survival in simultaneous liver/kidney transplantation for hepatitis C. Transpl Int 2014;27(06):606-616
40 Levitsky J. Next level of immunosuppression: drug/immune monitoring. Liver Transpl 2011;17(Suppl 3):S60-S65

41 Janetzki S, Britten CM; MIATA Core Team. The role of the reporting framework MIATA within current efforts to advance immune monitoring. J Immunol Methods 2014;409:6-8

42 Gambato M, Lens S, Navasa M, Forns X. Treatment options in patients with decompensated cirrhosis, pre- and post-transplantation. J Hepatol 2014;61(1, Suppl):S120-S131 